\title{
High-Performance Generator for a New Generation of Aircrafts
}

\author{
Ismagilov Flur ${ }^{1}$, Khayrullin Irek ${ }^{2}$, Vavilov Vyacheslav ${ }^{3}$, Karimov Ruslan $^{4}$, Gorbunov Anton $^{5}$ \\ Department of Electromechanics, Ufa State Aviation Technical University
}

\begin{tabular}{|c|c|}
\hline Article Info & ABSTRACT \\
\hline Article history: & The article describes multidisciplinary design process of high-performance \\
\hline Received Apr 20, 2017 & $\begin{array}{l}\text { electric generator for advanced aircrafts by analytical methods and computer } \\
\text { modeling techniques (electromagnetic, thermal and mechanical calculations). }\end{array}$ \\
\hline Revised May 23, 2017 & New technical solutions used in its development are described. The main \\
\hline Accepted June 11, 2017 & $\begin{array}{l}\text { ideas are revealed of the method of EG voltage stabilization we used. To } \\
\text { improve the heat dissipation efficiency, we have developed a new cooling }\end{array}$ \\
\hline Keywords: & $\begin{array}{l}\text { system, and provide its study and description in this paper. The advantages of } \\
\text { this cooling system include the fact that EG is made with dry, uncooled rotor. }\end{array}$ \\
\hline Electric generator & This allowed eliminating additional pumps, and significantly reducing the \\
\hline Electric machine & size of CSD. According to the results of our study, we created an \\
\hline More electric aircraft & experimental full capacity layout, and its studies are also provided in this \\
\hline Permanent magnets & \\
\hline
\end{tabular}

Copyright $@ 2017$ Institute of Advanced Engineering and Science. All rights reserved.

\section{Corresponding Author:}

Vavilov Vyacheslav,

Department of Electromechanics,

Ufa State Aviation Technical University,

450008, Russian Federation, Ufa, K. Marx Street 12,

Email: s2_88@mail.ru

\section{INTRODUCTION}

Electric generators (EG) for advanced power supply systems of autonomous objects play a very important role in today's aerospace industry. Power, reliability and EG weight and size characteristics largely determine functionality, performance and fuel efficiency of civil and military aircrafts (A/C) [1]. Electrical machines, which eliminate pneumatic or hydraulic constant speed drive are promising to improve A/C efficiency (electric machines made to a variable speed, similar to Boeing 787 starter-generators) or electrical machines, integrated in the aircraft engine or auxiliary power plant without gear [2-5]. [2] provide multicriteria selection of the type of a high-speed electrical machines for the aerospace industry. This analysis shows that the use of electrical machines with permanent magnets (PM) is the most effective. The similar conclusion was obtained in [3] - [9]. [10] also describes a high speed EG for commercial A/C. there are almost no papers devoted to the design and development of EG with PM in A/C systems with constant rotor speed of not more than 24,000 rpm and an output voltage of $400 \mathrm{~Hz}$, except publications [11], [12] which does not describe the process of designing and creating such EG, and describe methods of protection of EG with PM from short circuit.

Output voltage with a frequency of $400 \mathrm{~Hz}$ is provided by EG, which are integrated into a constant speed drive (CSD) with a rotor speed of not more than 24,000 rpm. Although, as was shown above, the prospect is to get rid of CSD, the use of CSD for some aircrafts (military and transport aviation) is a technical solution that provides the required reliability of $\mathrm{A} / \mathrm{C}$, and eliminating this unit is economically and technically inexpedient at this stage. Therefore, in addition to the development of promising directions for creating integrated electric machines for aircrafts, it is also very important to improve power characteristics of EG integrated in CSD of $\mathrm{A} / \mathrm{C}$, while minimizing their weight and size, and this task is not fully disclosed in the publications. 
To solve this problem, our research team in the interests of our industrial partner, has designed a high-performance EG with permanent magnets (PM), a power of $100 \mathrm{~kW}$, with a weight of $22 \mathrm{~kg}$. Together with this EG, we developed a voltage stabilization system weighing $10 \mathrm{~kg}$. EG is configured to 24,000 rpm, with an output frequency of $400 \mathrm{~Hz}$ (two-pole rotor) and designed to be integrated in the fixed speed hydraulic actuator of $\mathrm{A} / \mathrm{C}$. This paper describes multidisciplinary design process (electromagnetic, thermal and mechanical calculations) of the developed EG, as well as new technical solutions used in its creation, including the main ideas of EG voltage stabilization method that we used. To improve heat dissipation efficiency, we have developed a new cooling system also described in this paper. The advantages of this cooling system include the fact that EG is made with a dry, uncooled rotor. This eliminated additional pumps and significantly reduced CSD size. According to the results of our study, we made a full capacity experimental layout also described in this paper.

\section{REQUIREMENTS FOR EG AND EG TOPOLOGY SELECTION}

Specifications of the developed EG for advanced A/C with CSD, were given by our industrial partner. The main ones are:

1. Rated power of EG - $100 \mathrm{kVA}$;

2. Rated voltage $-115 / 200 \mathrm{~V}$;

3. The number of phases -3 ;

4. Nominal frequency of the alternating current $-400 \mathrm{~Hz}$ at a nominal EG shaft rotational frequency of 24,000 rpm;

5. EG operational load: $100 \mathrm{kVA}$.

6. EG overloads:

7. Long-term operating power of $150 \mathrm{kVA}$ for not more than 5 minutes;

8. Overload capacity of $200 \%$ of the generator rated power of $200 \mathrm{kVA}$ for 5 seconds.

The industrial partner has also established very strict limits on the length: the total length of EG (taking into account frontal parts) was not to be greater than $145 \mathrm{~mm}$, weight and overall dimensions of EG together with the control system - not more than $35 \mathrm{~kg}$. With all of this, EG and its control system were to ensure quality of the output power within MIL STD 704IE.

From the analysis of publications, as well as from practical experience of EG designing, we have found that the only EG type able to provide these characteristics is EG with permanent magnets (PM). At the same time to reduce the overall dimensions of EG with PM, it is appropriate to use the tooth winding [13-15]. At the same time the use of tooth winding results in significant harmonic distortion of the output voltage of EG due to spatial harmonics of MMF. To reduce these distortions and EG output power compliance with the requirements of MIL STD 704IE, a frequency converter at full power equal to EG power is used together with EG with tooth winding. But even the use of the most advanced element base does not allow to create a rectifier or frequency converter with a power of $100 \mathrm{~kW}$ and a weight of less than 22-25 kg [16]. Given that our industrial partner has established the requirements to EG weight with the control system was not more than $35 \mathrm{~kg}$, and EG rotor speed - not more than 24,000 rpm, it is evident that the use of frequency converter and EG with tooth winding in this case is not possible. At a weight of frequency inverter of $25 \mathrm{~kg}$, EG had to weigh not more than $10 \mathrm{~kg}$ and provide power of $100 \mathrm{~kW}$ at a speed of $24,000 \mathrm{rpm}$, and overload capacity of $150 \mathrm{~kW}$ also at 24,000 rpm. At this stage of development, practical implementation of these parameters is not possible.

Therefore, we have chosen topology of EG with PM with distributed winding and two-pole magnetic system, Figure 1, which made it possible to improve the output voltage quality. In order to stabilize EG output voltage, we used not a serial frequency converter at full power, but parallel one at power of not more than $40 \%$ of the rated power, Figure 2. This converter (digital module (DM)) is designed to stabilize voltage with the change in the load to EG at a constant rotor speed. Permanent frequency is provided by CSD. The essence of the control method used and EG output voltage stabilization is in fact that voltage is controlled by the magnetic field of EG response anchors by inductive or capacitive current generated by DM. DM is connected parallel to the load upstream EG feeder and consumes current shifted relative to voltage EG strictly to $\pm 90^{\circ}$. Thus DM intensifies the magnetic field of EG response anchors and reduces its voltage (inductive current), or lowers the magnetic field of armature reaction and increases EG voltage (capacitive current). In this case, DM current is reactive for EG and does not generate additional heat losses in EG winding and mechanical load on the shaft.

To protect against short circuits, EG phases are connected to star configuration through bidirectional semiconductor switches that open in short-circuit (SC), thereby isolating the point of short circuit. The solution used is similar to the solution proposed by Honeywell International [17], but our solution uses new algorithms to improve performance of the whole protection system. It would be more efficient to use a 
highly inductive EG (High-reactance permanent magnet machine), but since short-circuit current is not much higher than the rated current in this type of electric machines, we would not be able to fulfill the requirements for overload, established by our industrial partner. Therefore, we rejected this solution at the stage of topology selection.

To maximize heat dissipation, we used our developed and patented EG cooling system [18]. The uniqueness of this cooling system is that it uses two counter flows of cooled liquid, Figure 3, while providing uniform and effective heat dissipation.

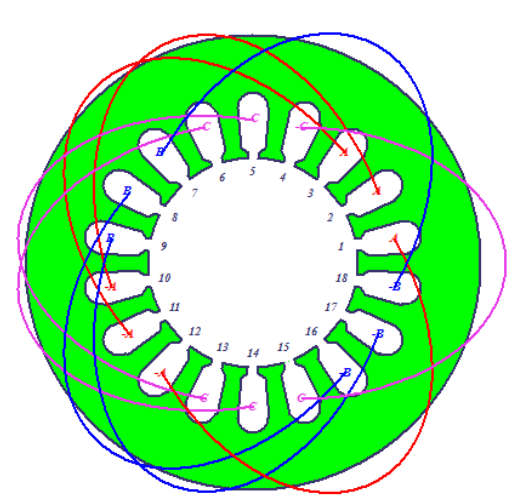

Figure 1. EG winding connection scheme

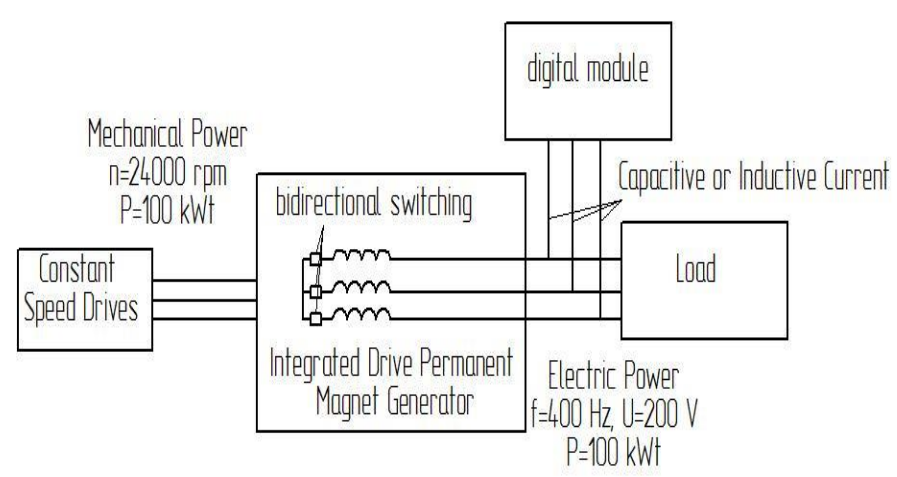

Figure 2. Schematic diagram of EG with DM

This EG liquid-cooling system operates as follows: the pump is pumping the coolant through the inlet fittings, which is simultaneously supplied to the first manifold and the second manifold where the front parts are installed. By washing the front parts, the coolant from the first and the second manifolds enters the coolers, made in the form of a cylinder with helical channels, and the coolant flows from the first and the second manifolds oppositely and then flows out through the outlet fitting. To prove effectiveness of all of the technical solutions, it is necessary to make multidisciplinary EG calculations. The algorithm proposed in [19, 20] was adopted as a basis in multidisciplinary calculations.



Figure 3. Structural diagram of EG cooling system

\section{ELECTROMAGNETIC CALCULATIONS OF EG}

In electromagnetic calculations, we have initially used the analytical expressions to calculate the preliminary geometrical dimensions of EG. After that, based on these geometric dimensions, a finite element model was developed. Sm2Co17 with residual induction $B_{r}$ not less than $1.1 \mathrm{~T}$ and permanent magnet coercive force in terms of magnetization of $H_{C}=812 \mathrm{kA} / \mathrm{m}$ are used as a material of permanent magnets. The maximum preliminary temperature of $\mathrm{PM}\left(\Theta_{\mathrm{pm}}=175^{\circ} \mathrm{C}\right)$ is defined on the basis of empirical data.

Based on this, characteristics of a permanent magnet are determined at the maximum operating temperature: 


$$
\begin{aligned}
& B_{r}(\Theta)=B_{r}\left(1-\frac{k_{B r}\left(\Theta_{p m}-23\right)}{100}\right)=1,05 T \\
& H_{b}(\Theta)=H_{b}\left(1-\frac{k_{H c}\left(\Theta_{p m}-23\right)}{100}\right)=600 \mathrm{kA} / \mathrm{m}
\end{aligned}
$$

Based on empirical data, preliminary rotor diameter and PM thickness is given: $D_{p}=100 \mathrm{~mm}, h_{m}=11 \mathrm{~mm}$.

Based on the thickness of permanent magnets, rotor bandage sheath is determined according to [20]. The total thickness of bandage sheath was $2.2 \mathrm{~mm}$ made of carbon fiber, while the relative air gap of the generator is equal to:

$$
\delta=\frac{2 \delta}{D_{p}}=\frac{2 * 0.003}{0.1}=0,06 \mathrm{~mm}
$$

The coefficients taking into account the change in the magnetic induction vector along the air gap length are determined:

$$
k_{z}=\frac{1}{p \delta^{*}} \frac{\left(1+\delta^{*}\right)^{2 p}-1}{\left(1+\delta^{*}\right)^{2 p}+1}=0,97
$$

A coefficient taking into account the fall in MMF in steel sections

$$
k_{F}=1,15
$$

Dissipation coefficient:

$$
k_{p}=1,15
$$

Induction in the air gap at idle can be determined by expression [21]:

$$
B_{\delta 0}=\frac{1}{1+\left(\frac{2 \delta}{2 h_{m}}\right) k_{z}\left(\frac{1}{\mu_{0}}\right)\left(\frac{B_{r}}{k_{p} H_{c}}\right)} \frac{B_{r}}{k_{p}}=0.694 \mathrm{~T}
$$

Further, according to Arnold equation, a linear current generator load is determined:

$$
\begin{aligned}
& A=\frac{6,03 P}{D_{p}^{2} l \alpha_{k} f k_{w} k_{z} B \delta l}= \\
& =\frac{6,03 * 100000}{(0,1)^{2} 0,115 * 0,85 * 0,92 * 1,27 * 24000 * 0,66 * 0,97} \approx 33100 \frac{\mathrm{A}}{\mathrm{m}}
\end{aligned}
$$

The number of slots per pole and phase

$$
q=3
$$

The number of teeth

$$
z=2 \cdot m \cdot p \cdot q=2 \cdot 3 \cdot 1 \cdot 3=18
$$

Then, the number of effective conductors in the slot: 
$N=\frac{\pi a D_{S} A}{Z_{1} I_{\mathrm{n}}}=\frac{3,14 * 1 * 0,106 * 33100}{18 * 306,22}=1,99$

$N=2$

Adjusted value of the linear current load:

$A=\frac{Z_{1} I_{\mathrm{n}} N}{\pi a D_{S}}=\frac{18 * 306,22 * 2}{3,14 * 1 * 0,106} \approx 33120 \frac{\mathrm{A}}{\mathrm{m}}$

Then the effective windings in the stator winding phase:

$w=2 p q \frac{N}{2} \frac{1}{a}=6$

Idling EMF [24, 25]:

$$
\begin{aligned}
& E=\frac{4 k_{w} k_{f} f B \delta 0 D_{p} l w_{f} \pi}{p}= \\
& =4 * 0.92 * 1.11 * 400 * 0.694 * 0.1 * 0.115 * 6=122,83 \mathrm{~V}
\end{aligned}
$$

According to the obtained geometric dimensions, a computer model was developed in Ansoft Maxwell software package. The simulation results are given in Figure 4. Upon the results of computer simulation (Figure 4), the results of preliminary settlement calculations were confirmed, and certain basic parameters of EG were determined, Table 1. EG calculations were performed under load and overload. Furthermore, the results of computer simulation show that the maximum induction in the stator yoke is not more than $2 \mathrm{~T}$, which is permissible for CoFe alloy. In building the external characteristics of EG, we used the known technique to describe the external characteristics with the ellipse equation.

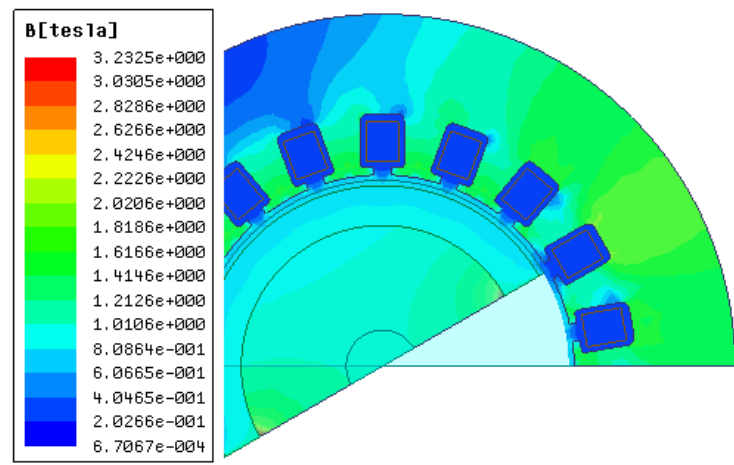

Figure 4. The results of EG computer simulation

In this case, inter alia, in building the external characteristic, we took into account the change in PM characteristics due to temperature.

$$
\left(\frac{U}{E_{0}}\right)^{2}+\left(\frac{I}{I_{k}}\right)^{2}+2\left(\frac{U}{E_{0}} \frac{I}{I_{k}}\right) \cos \left(\phi-\operatorname{arctg} \frac{x_{d}}{r_{a}}\right)=1
$$

PM flowchart was built to determine current Ik, and it was found from it that Ik for the operating temperature of $175^{\circ} \mathrm{C}$ is $14173 \mathrm{kA}$. Given these values, and also based on calculations in Table 1, we have built the external EG characteristic, Figure 5. 


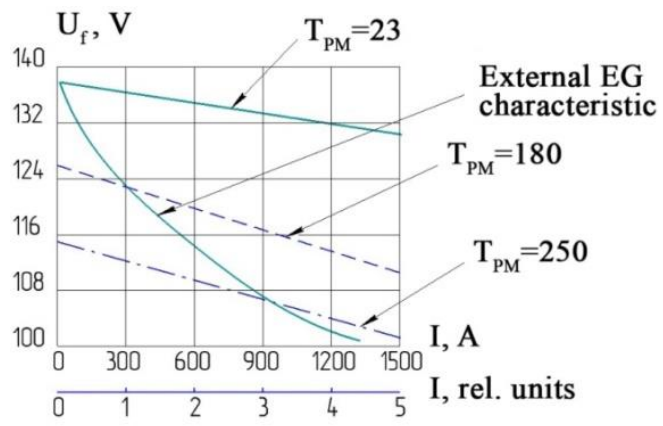

Figure 5. The external EG characteristic

Table 1 shows that the developed generator has a current density in the winding of $12 \mathrm{~A} / \mathrm{mm}^{2}$, which corresponds to the selected cooling system. At the same time, it is able to withstand three times multiplicity of demagnetization current, which also corresponds to the requirements for aircraft generators of this type. Specific electric loading of the designed generator also does not exceed the limits for the selected cooling system. Therefore, it can be concluded that the calculated data obtained in Table 1 fully satisfy the task.

As a result of electromagnetic calculations, a certain main structural diagram of EG and its parameters were determined, which fully meet the conditions set by our industrial partners.

Figure 5 shows that the external characteristic of the generator being developed is affected both by electric parameters, and also to a great extent by thermal processes. The external characteristic becomes nonlinear when they are taken into account.

Table 1. Results of EG parameters calculations determined as a result of computer simulation

\begin{tabular}{lll}
\hline Active area steel grade & - & $\mathrm{CoFe}$ \\
Thickness of sheets & $\mathrm{mm}$ & 0.07 \\
Phase current frequency & $\mathrm{Hz}$ & 400 \\
Phase voltage & $\mathrm{V}$ & 124 \\
Phase current (rms) & $\mathrm{A}$ & 306,22 \\
Current density in the winding & $\mathrm{A} / \mathrm{mm}^{2}$ & 12,2 \\
Specific Electric Loading & $\mathrm{A} / \mathrm{m}$ & 33104 \\
Heat factor & $\mathrm{A} / \mathrm{mm}^{2} *$ & 3972 \\
& $* \mathrm{~A} / \mathrm{sm}^{2}$ & \\
Generator power & $\mathrm{kVA}$ & 108 \\
Shortening coefficient & - & 0,965 \\
Distribution coefficient & - & 0,957 \\
Active resistance and dissipation resistance & $\mathrm{Ohm}$ & $0,00268 / 0,0255$ \\
Multiplicity of demagnetization current & - & 3,3 \\
Inductive phase resistance along axes d-q & $\mathrm{Ohm}$ & $0,099 / 0,099$ \\
\hline
\end{tabular}

\subsection{Calculations of EG rotor mechanical strength}

The developed EG has a sufficiently larger rotor diameter at relatively high speed, so it is necessary to make more accurate calculations of mechanical strength of rotor bandage sheath.

At a thickness of the sheath of $2.2 \mathrm{~mm}$, and taking into account the mass of magnets $(2.6 \mathrm{~kg})$, centrifugal forces were calculated acting on the rotor bandage taking into account increased speed $(28,800$ rpm):

$$
F=\omega^{2} R m_{\text {mag }}=3015^{2} \cdot 0.05 \cdot 2,6 \approx 1181729 H
$$

where $\omega$ is the rotor speed $(24,000 \mathrm{rpm}$ or $2,514 \mathrm{rad} / \mathrm{sec}$ ), $\mathrm{R}$ is the rotor radius (determined from electromagnetic calculations and is $50 \mathrm{~mm}), m_{\mathrm{mag}}$ is the mass of the magnets is $2.6 \mathrm{~kg}$.

Taking into account the geometric parameters and the resulting magnitude of centrifugal forces, a finite element model was developed in Solid Works software package, and stress in the rotor sheath was calculated as, Figure 6. Figure 6 shows that the stresses in the rotor sheath do not exceed $609 \mathrm{MPa}$, and this provides a safety factor for the projected generator of 1.76. The above calculations confirm performance of the proposed design. 


\section{EG ROTOR DYNAMICS ANALYSIS}

A rotor developed at the stage of electromagnetic calculation is considered when calculating the critical rotor speed. The problem of dynamics analysis was solved using Ansys software package, Figure 7.

As a result of the calculation (Figure 7), it was found that the maximum lateral force acting on the rotor is $2,652 \mathrm{~N}$, the first critical speed is at $98,000 \mathrm{rpm}$, i.e. is much higher than the rated speed. This proves performance of the selected constructive scheme of the rotor.

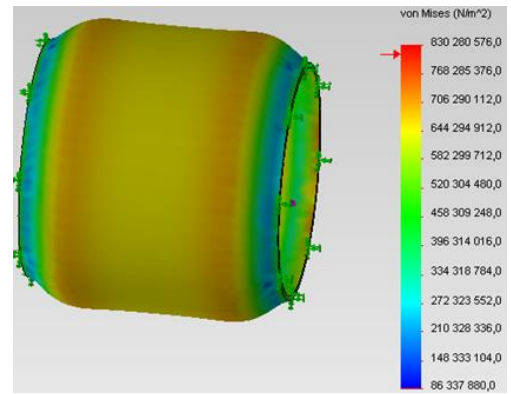

Figure 6. Calculations made in Solid Works software package

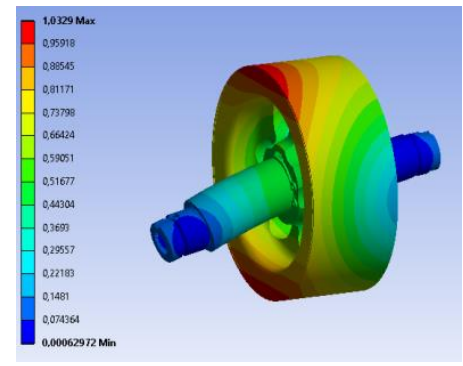

Figure 7. Deflection of the magnetoelectric generator rotor at the first critical rotation speed

\section{CALCULATION OF LOSSES AND EVALUATION OF EG EFFICIENCY, AND COOLING SYSTEM CALCULATION}

EG loss calculation is an important step in the design. Due to the limited EG volume, total losses in the active elements should be calculated as accurately as possible, to ensure maximum heat dissipation and reliability of EG. Mechanical losses in EG can be determined according to the procedure given in [22]. Losses in Co-Fe alloys for $400 \mathrm{~Hz}$ are usually specified by the manufacturer [23], and can be estimated based on the weight of the magnetic circuit and the magnetic flux density values obtained in electromagnetic calculations, Figure 5. Particular attention should be paid to losses for eddy current in permanent magnets, since the rotor in the developed EG is not cooled, and there will be virtually no heat dissipation from PM. Losses in PM were calculated by finite element method, Figure 8.

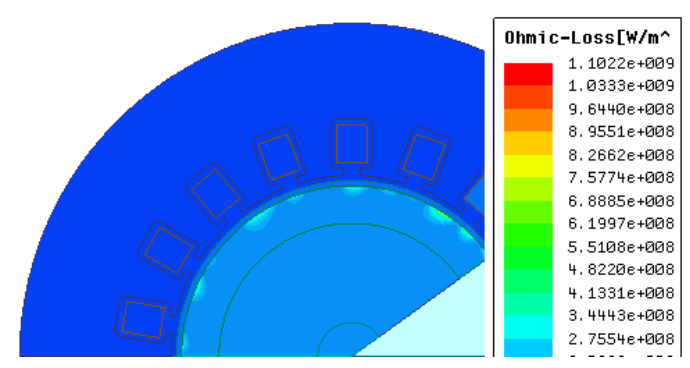

Figure 8. Distribution of losses for eddy currents in PM

Results EG loss calculations are shown in Table 2. Based on this calculation, the cooling system was designed described above. The estimate of temperatures by finite element method showed that the maximum $\mathrm{PM}$ temperature is not more than $180{ }^{\circ} \mathrm{C}$, and winding temperature is not more than $205{ }^{\circ} \mathrm{C}$, which fully provides EG performance.

Table 2. Losses in active EG elements

\begin{tabular}{lcc}
\hline Ohmic losses in the stator copper & W & 1,154 \\
Losses in steel & W & 693 \\
Surface losses in the rotor due to tooth harmonics of the stator & W & 193 \\
Losses in the winding due to proximity effect and eddy currents & W & 528 \\
\hline
\end{tabular}


Analysis of Table 2 shows that the developed aircraft electric generator has a sufficiently high efficiency. Total losses in the designed structure do not exceed $2.6 \mathrm{~kW}$, which at an electric power of $100 \mathrm{~kW}$ provides efficiency of $97 \%$. Maximum losses take place in the stator winding, while losses are not significant in the stator iron. Minimum losses in the stator iron were achieved due to the use of the siliceous electrical steel with a sheet thickness of $0.18 \mathrm{~mm}$. In general, as shown by thermal analysis, all these losses are diverted by the selected cooling system, which confirms workability of the developed electric generator in terms of thermal loads.

\section{EG VOLTAGE CONTROL AND STABILIZATION SYSTEM}

An important task in creating EG is the design of its control system, implementing the method described above. A block diagram of the control method and voltage stabilization implemented by DM, is shown in Figure 9.

To confirm efficiency of the proposed control and stabilization method for the output voltage of A/C EG and prove its practical implementation, the authors have developed a simulation model of generation channel in Matlab software package, which allows evaluating efficiency of the proposed control and stabilization method for EG output voltage, as well as duration of transients, voltage stabilization accuracy and to obtain DM adjustment characteristics.



Figure 9. Block diagram of EG control method

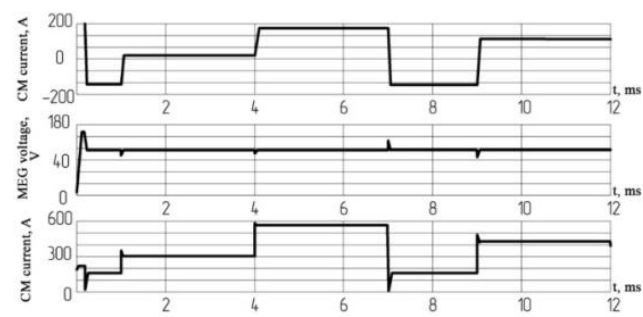

Figure 10. Simulation results of EG control processes (CM current, A VS t, ms; MEG voltage, A VS t, ms; CM current, A VS t, ms)

The developed simulation model consists of several units: a load unit (Load), DM unit including Current Regulator and Solver, as well as drive-generator unit (Generator). EG model is implemented in dq coordinates, and allows simulating operation of EG in generator mode as part of a constant speed drive in the range of loads from idling to three-fold overload. The simulation takes into account EG with the following numerical parameters: speed $-24,000 \mathrm{rpm}$, rated power $-100 \mathrm{kVA}$, frequency of the generated voltage -400 $\mathrm{Hz}$, magnetic induction in the air gap $-0.66 \mathrm{~T}$. As a result of the simulation, Figure 10, DM current values were obtained, as well as voltage and current of the generator at a sharp change of the load and adjustment characteristic of DM, Figure 11. The analysis of simulation results Figure 10 shows that the proposed EG voltage control and stabilization method is efficient and allows controlling EG voltage over a wide range of load changes. Also the simulation results show that the maximum duration of the transient process is observed when the load changes from two-fold overload up to idling and is $70 \mathrm{~ms}$. In this case the generator voltage reaches $140 \mathrm{~V}$, that is, increased by $21.7 \%$, and then restored to the nominal value.

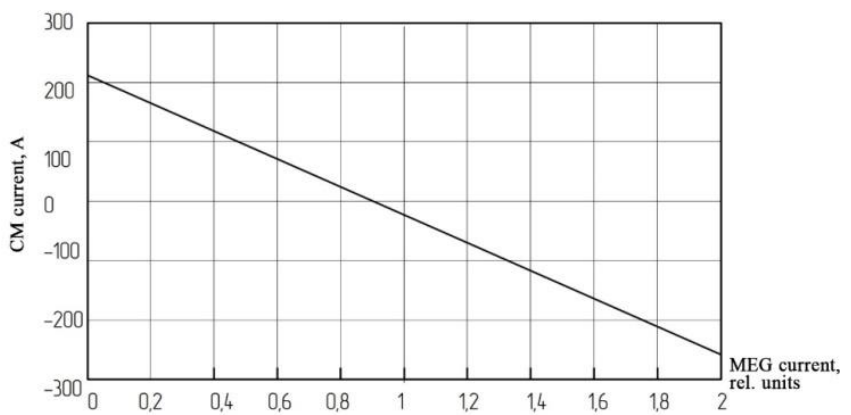

Figure 11. EG adjustment characteristics (CM current, A VS MEG current, rel. units) 
As seen in Figure 11, DM current varies in the range of $0 \mathrm{~A}$ at $80 \%$ load to $200 \mathrm{~A}$ at idling or $160 \%$ load. In this case, in generator idling mode, DM current is behind voltage, and in overload mode - it is ahead by $90^{\circ}$, which also confirms validity of the proposed voltage control method.

\section{EXPERIMENTAL EG LAYOUT}

Based on the results, by the geometric dimensions, Table 1, full power EG demonstration layout was developed, as well as the layout of its control system was designed, Figure 12, 13.

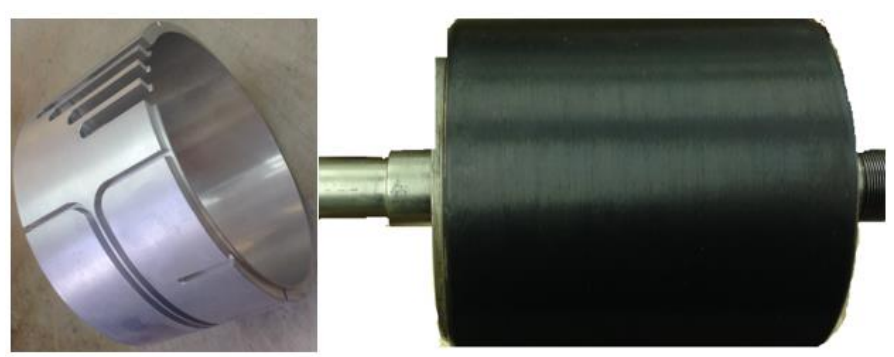

Figure 12. EG cooling jacket (left) and EG rotor (right)

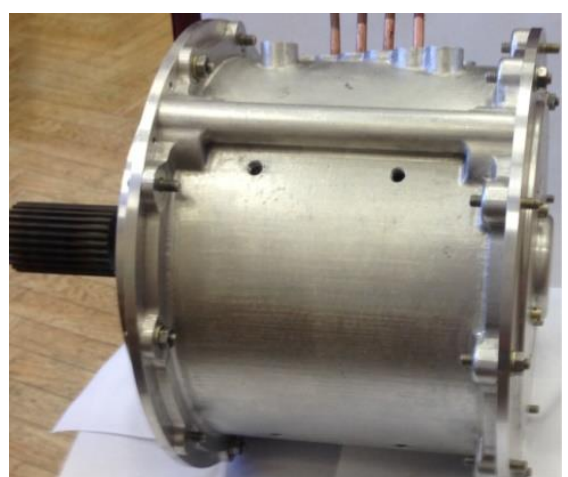

Figure 13. Full-size EG layout (left)

As a result of research, the effectiveness of our solution has been fully proved, and all technical requirements specified by our industrial partner were complied with. A further step in our research was stand tests simulating $\mathrm{A} / \mathrm{C}$ systems.

\section{RESULTS AND CONCLUSIONS}

Thus, the paper describes a process of multidisciplinary design of a high-performance EG with permanent magnets $(\mathrm{PM})$, power of $100 \mathrm{~kW}$, weight of $22 \mathrm{~kg}$. Together with this EG, we have developed a system of voltage stabilization weighing $10-12 \mathrm{~kg}$. EG is configured to $24,000 \mathrm{rpm}$, with an output frequency of $400 \mathrm{~Hz}$ (two-pole rotor) and is designed for integration into CSD of A/C.

Comparing our results with works of other authors, we can conclude that the new aircraft generator that we have created has minimized mass parameters at sufficiently high energy values. The control system proposed by us is of particular value in this case, which also outperforms analogs in terms of mass parameters. At the same time, the mass in aerospace industry is the main criterion for making decisions, since it allows to significantly minimize the economic costs associated with the fuel efficiency of the aircraft. Table 3 provides comparisons of our generator and known aircraft electric generators described in [1] - [18].

Table 3. Comparison of the developed generator and other types of generators with permanent magnets, used on various aircrafts

\begin{tabular}{|c|c|c|c|c|}
\hline & $\begin{array}{c}\text { Developed } \\
\text { power generator }\end{array}$ & $\begin{array}{l}\text { Electric generator } \\
\text { with permanent } \\
\text { magnets and bias } \\
\text { windings }\end{array}$ & $\begin{array}{l}\text { Electric generator with } \\
\text { permanent magnets and } \\
\text { full power inverter }\end{array}$ & Combined excitation generator \\
\hline $\begin{array}{l}\text { Rated/overload } \\
\text { power, kW }\end{array}$ & $100 / 150$ & $100 / 150$ & $100 / 150$ & $100 / 150$ \\
\hline $\begin{array}{l}\text { Generator weight, } \\
\text { kg }\end{array}$ & 24,2 & 27,2 & 20,2 & 34 \\
\hline $\begin{array}{l}\text { Control system } \\
\text { weight, } \mathrm{kg}\end{array}$ & 12 & 11 & 25 & 5 \\
\hline $\begin{array}{c}\text { Total system weight, } \\
\text { kg }\end{array}$ & 36,2 & 38,2 & 45,2 & 39 \\
\hline $\begin{array}{l}\text { Losses in the stator } \\
\text { magnetic circuit, W }\end{array}$ & 693 & 693 & 700 & 1050 \\
\hline Losses in rotor, $\mathrm{W}$ & 193 & 210 & $300-350$ & 700 \\
\hline $\begin{array}{c}\text { Aerodynamic losses, } \\
\text { W }\end{array}$ & 26 & 26 & 26 & 120 \\
\hline Ohmic losses in the & 1154 & 1154 & 1200 & 1154 \\
\hline
\end{tabular}


main winding, $\mathrm{W}$ Additional losses, W Total losses, W

The analysis of Table 3 shows that since the rectifier and the full power inverter are not used together with our generator, the eddy current losses in it created in permanent magnets are lower than in other options. This is due to the fact that in our generator the eddy current losses are induced only because of the spatial harmonics of MMF, the time harmonics in our generator are not significant. In other competing options, losses in permanent magnets are greater, since the time harmonics are significant in them. The combined excitation generator is also inferior to our solution both in terms of efficiency and mass of the system.

Table 3 shows that our system has minimal mass-dimension parameters and minimal energy losses. And this, in the aggregate, shows the high efficiency of the solution developed. All this is achieved due to the optimal electric generator design. The basis of this method was set forth by us in [24], and also thanks to the use of a new method of stabilizing the generator voltage. Our conclusions are confirmed by the results of experimental studies of the full-size model.

\section{ACKNOWLEDGEMENTS}

The work is done in the framework of the project 8.1277.2017/HR "Research, development and introduction of advanced Electromechanical converters for Autonomous objects with a hybrid power plant"

\section{REFERENCES}

[1] Van Der Geest, et al., "Machine selection and initial design of an aerospace starter/generator," in 2013 IEEE International Electric Machines and Drives Conference, IEMDC 2013, Chicago, IL, United States, 12 May 2013 through 15 May 2013, Code 98445.

[2] E. Ganev "Selecting the Best Electric Machines for Electrical Power Generation Systems," IEEE Electrication Magazine, December 2014.

[3] Lahne Hans-Christian and Gerling Dieter "Investigation of High-performance Materials in Design of a $50000 \mathrm{rpm}$ Highspeed Induction Generator for Use in Aircraft Applications," AST, 2015, pp. 1-10.

[4] K. Rajashekara, et al., "Hybrid Fuel Cell Power in Aircrafrt: A feasibility study for onboard power generation using a combination of solid oxide fuel cells and gas turbines," IEEE Industry Application Magazine, 2008, Vol. 14, No. 3, pp. 54-60.

[5] Xin Zhao, et al., "Review of aircraft electric power systems and architectures," in Energy Conference (ENERGYCON), IEEE International, 2014, pp. 949-953.

[6] R. I. Jones "The More Electric Aircraft: the past and the future," Electrical Machines and Systems for the More Electric Aircraft, 1999, pp. 1/1-1/4.

[7] M. Tosetti, et al., "Conjugate heat transfer analysis of integrated brushless generators for more electric engines," 5th Annual IEEE Energy Conversion Congress and Exhibition. ECCE 2013, Denver, CO, United States, 15 September 2013 through19 September 2013. pp. 1518-1525.

[8] R. Bojoi, et al., "Control of shaft-line-embedded multiphase starter/generator for aero-engine," IEEE Transactions on Industrial Electronics, 2016, pp. 641-652.

[9] A. Cavagnino, et al., "Integrated generator for more electric engine: Design and testing of a scaled-size prototype," IEEE Transactions on Industry Applications, 2013, Vol. 49. Issue 5, pp. 2034-2043.

[10] P. Arumugam, et al., "Permanent Magnet Starter-Generator for Aircraft Application," SAE Technical Paper 201401-2157, 2014. DOI:10.4271/2014-01-2157.

[11] E. D. Ganev, "High-performance electric drives for aerospace more electric architectures part I - Electric machines," IEEE Power Engineering Society General Meeting, 2007, PES 4275345.

[12] E. Ganev, "High-Reactance Permanent Magnet Machine for High-Performance Power Generation Systems," SAE Technical Paper 2006-01-3076, 2006. DOI:10.4271/2006-01-3076.

[13] Dieter Gerling and Mohammed Alnajjar, "Six-Phase Electrically Excited Synchronous Generator for More Electric Aircraft," International Symposium on Power Electronics, Electrical Drives, Automation and Motion, 2016, pp. $7-$ 13.

[14] F. Magnussen, and Ch. Sadarangani, "Winding factors and Joule losses of permanent magnet machines with concentrated windings," in 2003 IEEE International Electric Machines \& Drives Conference (IEMDC 2003), 0104.06, Madison, Wisconsin, USA.

[15] Gurakuq Dajaku, et al., "Comparison of Two FSCW PM Machines for Integrated Traction Motor/Generator," in 2015 IEEE International Electric Machines \& Drives Conference (IEMDC), pp. 187-194.

[16] J.-P. Besnard, et al., "Electrical rotating machines and power electronics for new aircraft equipment systems," ICAS-Secretariat - 25th Congress of the International Council of the Aeronautical Sciences, 2006.

[17] Evgeni Ganev, et al., "System and method for fault protection for permanent magnet machines," Patent US $7276871 \mathrm{~B} 2,2007$. 
[18] I. Kh. Khayrullin, et al., "Liquid cooling system for the stator of electric machines of autonomous facilities," Patent of the Russian Federation No. 2513042, 16.01.2013.

[19] N. Uzhegov, et al., "Multidisciplinary Design Process of a 6-Slot 2-Pole High-Speed Permanent-Magnet Synchronous Machine," IEEE Transactions on Industrial Electronics.

[20] Z. Tao, et al., "Strength Design on Permanent Magnet Rotor in High Speed Motor Using Finite Element Method," Telkomnika Indonesian Journal of Electrical Engineering, 2014, Vol. 12, No. 3. pp. 1758-1763.

[21] F. Ismagilov, et al., "Features of designing high-rpm electromechanical energy converters operating in short-term mode with high-coercivity permanent magnets," International Review of Electrical Engineering, Vol. 11, No. 1 (2016), pp. 28-35.

[22] A. Palmgren, "Ball and Roller Bearing Engineering," Philadelphia, PA, USA: SKF Industries Inc., 1959.

[23] H. C. Lahne and D. Gerling, "Comparison of High-Speed HighPower Machines based on the State of the Art," in 41st Annual Conference of the IEEE Industrial Electronics Society (IECON 2015), 2015. pp. 3519-3524.

[24] Yaling, W., Yanliang, X. A design study of dual-stator permanent magnet brushless DC Motor // Telkomnika, 11(4), pp. 653-660

[25] F. Ismagilov, V. Vavilov, V. Ayguzina, V. Bekuzin. New method of optimal design of electrical rotating machines // Indonesian Journal of Electrical Engineering and Computer Science, 5 (3), pp. 479-487.

\section{BIOGRAPHIES OF AUTHORS}
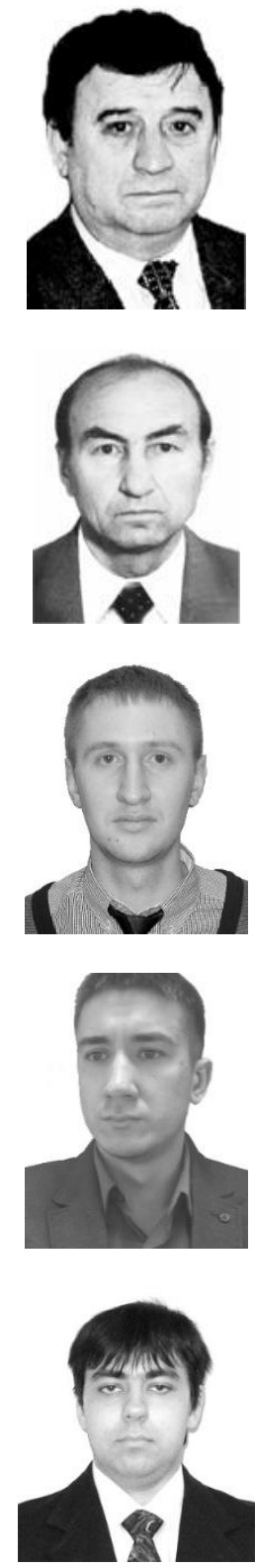

Flur R. Ismagilov, professor, head of lecturer Electromechanics, Ufa State Aviation Technical University, Ufa, Russia. In 1973 he graduated from the Ufa Aviation Institute Electromechanics, $\mathrm{Ph}$. D on the elements and control devices.

Irek Kh. Khayrullin, professor, department of electromechanics at the Ufa State Aviation Technical University Ufa, Russia, graduated from the Ivanovo Power Engineering Institute in 1963, Electromechanics faculty, Ph.D. in the elements and control systems.

Vyacheslav E. Vavilov, senior lecturer, department of Electromechanics, Ufa State Aviation Technical University Ufa, Russia. In 2010 he graduated from the Ufa State Aviation Technical University, majoring in electrical engineering. In 2013 he defended his thesis.

Ruslan D. Karimov, research assistant, department of Electromechanics, Ufa State Aviation Technical University Ufa, Russia. In 2010 he graduated from the Ufa State Aviation Technical University. Master of Engineering (USATU, 2012).

Anton S. Gorbunov, senior lecturer, department of Electromechanics, Ufa State Aviation Technical University Ufa, Russia. In 2011 he graduated from the Ufa State Aviation Technical University in the specialty «Electromechanics», Ph.D. in electrotechnical complexes and systems. 